\title{
EFFECT OF SCANNING SPEED WHEN MEASURing SuRFACE ROUGHNESS
}

\author{
Dana Kubátová, Martin Melichar
}
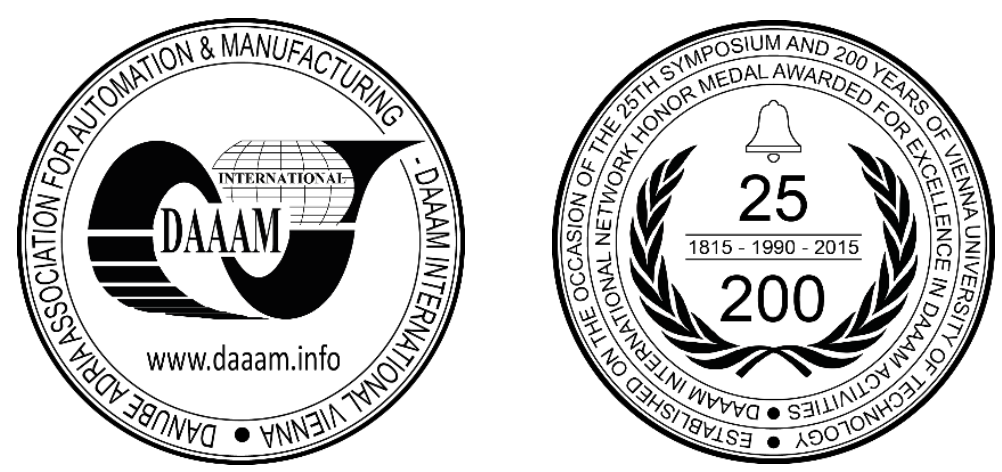

This Publication has to be referred as: Kubatova, D[ana] \& Melichar, M[artin] (2018). Effect of Scanning Speed when Measuring Surface Roughness, Proceedings of the 29th DAAAM International Symposium, pp.1249-1255, B. Katalinic (Ed.), Published by DAAAM International, ISBN 978-3-902734-20-4, ISSN 1726-9679, Vienna, Austria DOI: $10.2507 / 29$ th.daaam.proceedings. 180

\begin{abstract}
In the field of practical metrology it is extremely important not only accuracy but also the measurement of measuring productivity activities which entail considerable costs. Within this article, was tested the influence of the velocity for measuring of roughness. Test was made in in controlled laboratory conditions on the quality and accuracy of the measurements In this paper experiment described test that was performed on standard pieces with defined $\mathrm{Ra}$ and $\mathrm{Rz}$ values. The test was performed on the principle of repeated measurement at different speeds. The speed was 0.1-3 mm / $\mathrm{s}$, which is the range of Hommel Etami T 8000. This machine is currently used for calibration at the Czech Metrology Institute and is one of the leading machines for measuring roughness in technical practice. The results obtained clearly declare the effect on the results of the measured values. All measured data underwent statistical processing and subsequently verification of its accuracy.
\end{abstract}

Keywords: feed rate; D-optimal design; software filter; surface roughness

\section{Introduction}

Measurement and evaluation of surface texture have seen major qualitative advances in recent years. Leading producers of measuring instruments (Hommel, Carl Zeiss, and others) have responded actively to new requirements. Surface texture is frequently checked by means of single-purpose measuring instruments. For this reason, some of the key players who put pressure on developing standards related to evaluating the quality of measurement of machined surfaces are the manufacturers of such instruments themselves. [2] This has ultimately led to improved technologies of existing tools for surface texture measurement and evaluation, as well as to better methods, measuring systems and the system of assessment and evaluation of surface texture that are still under development. [6;7] The system of assessment and evaluation of surface texture is defined by a body of standards which describe designations, measurement, and evaluation of surface texture, calibration of measuring instruments, and other aspects. They are the GPS (Geometrical Product Specification) standards. [5] The motivation for this article was to verify the accuracy of the machine settings when measuring surface roughness. This test is part of an extensive project to set up a software filter selection methodology for measuring surface roughness. This is solved in the framework of research at the University of West Bohemia. The article describe last test for developing a method of selection of software filters for surface roughness measurement concerned the effects of the stylus speed. 


\section{Test design}

Design of experiment (DOE) techniques was used for designing this test. D-optimal design was selected for this test. The best model for testing surface roughness evaluation appears to be the response surface model. A cubic model was employed, as the highest-order mathematical model capable to characterize the design owing to the shape of the measured data curve.[2] For this test, the test factors, both controllable and fixed, must be defined, as well as the test response.

The controllable factors include (categorial + numerical models) the following:

- $\quad$ Roughness number - RA0.5; RA1; RA3.2; RA6.3

- $\quad$ Filter used - 16610-21; 16610-22; 16610-31; 4768; 0601

- Measuring speed $-0.1-3 \mathrm{~mm} / \mathrm{s}$ range

The fixed factors include:

- Stylus tip radius $-2 \mu \mathrm{m}$

- Direction of sensor movement - towards the column

- Calibration of the measuring instrument

- Machine settings for measurement $-\lambda \mathrm{c}=0.8 \mathrm{~mm} ; \mathrm{Lt}=4.8 \mathrm{~mm} ; \mathrm{Lc} / \mathrm{Ls}=$ off; point spacing=0.7 $\mu \mathrm{m}$

Response:

- Ra parameter

- Rz parameter

- Rv parameter

- Rsm parameter

Based on this input information, a plan was designed, which comprised 43 measurements using various speeds, filters and surface roughness values.

\section{Evaluation of test using a software tool}

The test was evaluated in several steps using MATLAB program. In the first step, a mathematical model of the measured data had to be developed for each roughness parameter under test. These models are presented in the tabular format. In each case, the green cells are relevant to the model in question.[3], [4]

The following parameters are significant to the Ra parameter: an unknown parameter (an unspecified parameter reflected in the roughness evaluation), measuring speed and surface roughness of the standard. In Table 1, the significance level of an effect is denoted by the letter $\mathrm{p}$ (where $\mathrm{p}$ is under 0.05 , the effect is significant to the model).

\begin{tabular}{|c|c|c|c|c|c|}
\hline \multirow{2}{*}{ Effect } & \multicolumn{5}{|c|}{$\begin{array}{c}\text { One-dimensional significance test for Ra [um] (ANOVA) } \\
\text { Sigma-effective hypothesis of limited parametrization }\end{array}$} \\
\cline { 2 - 6 } & SS & $\begin{array}{c}\text { Degree } \\
\text { of freedom }\end{array}$ & MS & F & p \\
\hline Unknown parameter & 176.4179 & 1 & 176.4179 & 15915.04 & 0.000000 \\
\hline A:speed [mm.s-1] & 0.5061 & 6 & 0.0843 & 7.61 & 0.000058 \\
\hline B:filter & 0.0420 & 4 & 0.0105 & 0.95 & 0.451404 \\
\hline C:standard [um] & 176.6132 & 3 & 58.8711 & 5310.88 & 0.000000 \\
\hline Error & 0.3215 & 29 & 0.0111 & & \\
\hline
\end{tabular}

Table 1. Results of one-dimensional test for Ra parameter

Results of the validity test for the model are plotted in Graph 1. A majority of measured data are very close to the curve that represents the model of individual effects on measured roughness. [3], [5] However, there is one value which lies farther from the model. It is indicated with a red ellipse.

After an in-depth examination, it was determined to be a result of gross error $( \pm 36)$. It was excluded from further processing but it is still plotted in the graph. 


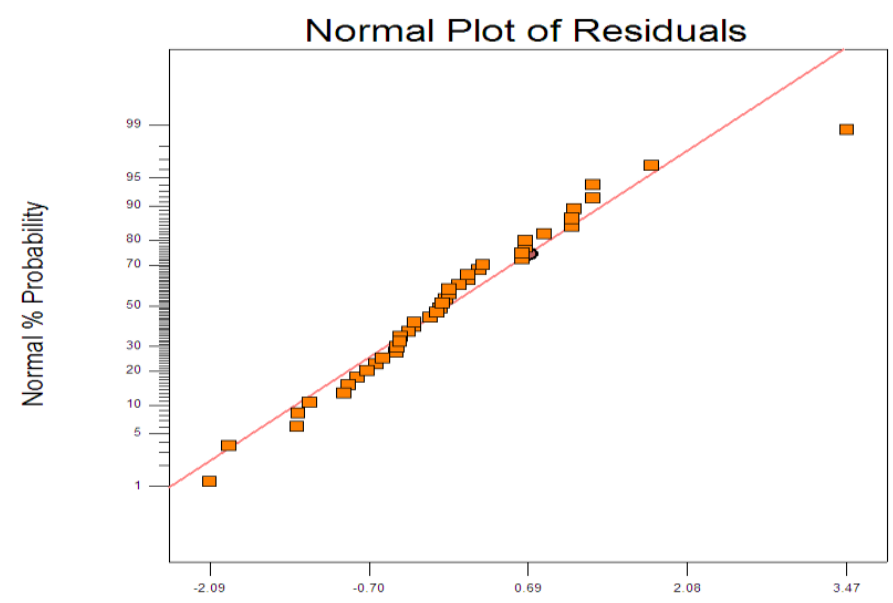

Fig. 1. Graphical verification of validity of the model for Ra parameter

The remaining roughness parameters were assessed using the same technique. Parameters relevant to Rz parameter: unknown parameter (an unspecified parameter reflected in roughness evaluation), measuring speed, the type of standard and, as opposed to Ra parameter; there is a certain role that the effect of a filter has to play. Details are given in Table 2. [6], [7]

\begin{tabular}{|c|c|c|c|c|c|}
\hline \multirow{2}{*}{ Effect } & \multicolumn{5}{|c|}{$\begin{array}{c}\text { One-dimensional significance test for Rz parameter [um] (ANOVA) } \\
\text { Sigma-effective hypothesis of limited parametrization }\end{array}$} \\
\cline { 2 - 6 } & SS & $\begin{array}{c}\text { Degree } \\
\text { of freedom }\end{array}$ & MS & F & p \\
\hline Unknown parameter & 2518.317 & 1 & 2518.317 & 22967.55 & 0.000000 \\
\hline A:speed [mm.s-1] & 21.090 & 6 & 3.515 & 32.06 & 0.000000 \\
\hline B:filter & 58.101 & 4 & 1.45 & 13.2 & 0.00284589 \\
\hline C:standard [um] & 2585.836 & 3 & 861.945 & 7861.11 & 0.000000 \\
\hline Error & 3.180 & 29 & 0.110 & & \\
\hline
\end{tabular}

Table 2. Results of one-dimensional test for Rz parameter

The conditions for both R2 and p parameters were met in regard to Rz as well - the model is fully valid in this case.

\begin{tabular}{|c|c|c|c|c|c|c|c|c|c|c|c|}
\hline \multirow{2}{*}{$\begin{array}{c}\text { Dependent } \\
\text { variable }\end{array}$} & \multicolumn{10}{|c|}{ SS test for the entire model vs. SS residuals (ANOVA) } \\
\cline { 2 - 10 } & Multiples & $\begin{array}{c}\text { Multiples } \\
\text { of R2 }\end{array}$ & $\begin{array}{c}\text { The coefficient } \\
\text { of determination }\end{array}$ & $\begin{array}{c}\text { SS } \\
\text { model }\end{array}$ & $\begin{array}{c}\text { df } \\
\text { model }\end{array}$ & $\begin{array}{c}\text { MS } \\
\text { model }\end{array}$ & $\begin{array}{c}\text { SS } \\
\text { variance }\end{array}$ & $\begin{array}{c}\text { df } \\
\text { variance }\end{array}$ & $\begin{array}{c}\text { MS } \\
\text { variance }\end{array}$ & F & p \\
\hline Rz $[\mathrm{um}]$ & 0.999512 & 0.999024 & 0.998586 & 3254.057 & 13 & 250.3120 & 3.179756 & 29 & 0.109647 & 2282.895 & 0.00 \\
\hline
\end{tabular}

Table 3. Results of verification test for Rz parameter

The effects relevant to Rsm parameter: unknown parameter and type of standard. It should be noted that neither the measuring speed nor the software filter used are relevant to evaluation of the Rsm parameters. [7,8]It follows from Table 3 which gives results of verification of validity of the model.

\begin{tabular}{|c|c|c|c|c|c|}
\hline \multirow{2}{*}{ Effect } & \multicolumn{5}{|c|}{$\begin{array}{c}\text { One-dimensional significance test for Rsm parameter [um] (ANOVA) } \\
\text { Sigma-effective hypothesis of limited parametrization }\end{array}$} \\
\cline { 2 - 6 } & SS & $\begin{array}{c}\text { Degree } \\
\text { of freedom }\end{array}$ & MS & F & p \\
\hline Unknown parameter & 0.637568 & 1 & 0.637568 & 25.01390 & 0.000025 \\
\hline A:speed [mm.s-1] & 0.090453 & 6 & 0.015075 & 0.59146 & 0.734426 \\
\hline B:filter & 0.057009 & 4 & 0.014252 & 0.55916 & 0.694056 \\
\hline C:standard [um] & 0.581442 & 3 & 0.193814 & 7.60396 & 0.000674 \\
\hline Error & 0.739168 & 29 & 0.025489 & & \\
\hline
\end{tabular}

Table 4. Results of one-dimensional test for Rsm parameter 
The results of R2 and p parameters are less definite in indicating the validity of the model for Rsm (Table 4). However, as the entire model describes all the parameters ( $\mathrm{Ra}, \mathrm{Rz}, \mathrm{Rsm}, \mathrm{Rv})$ using a single equation, it was decided that the model is valid in this case as well.

\begin{tabular}{|c|c|c|c|c|c|c|c|c|c|c|c|}
\hline \multirow{2}{*}{$\begin{array}{c}\text { Dependent } \\
\text { variable }\end{array}$} & $\begin{array}{c}\text { Multiples } \\
\text { of R R }\end{array}$ & $\begin{array}{c}\text { Multiples } \\
\text { of R2 }\end{array}$ & $\begin{array}{c}\text { The coefficient } \\
\text { of determination }\end{array}$ & $\begin{array}{c}\text { SS } \\
\text { model }\end{array}$ & $\begin{array}{c}\text { df } \\
\text { model }\end{array}$ & $\begin{array}{c}\text { MS } \\
\text { model }\end{array}$ & $\begin{array}{c}\text { SS } \\
\text { variance }\end{array}$ & $\begin{array}{c}\text { df } \\
\text { variance }\end{array}$ & $\begin{array}{c}\text { MS } \\
\text { variance }\end{array}$ & F & p \\
\hline Rsm $[\mu \mathrm{m}]$ & 0.698361 & 0.487709 & 0.258061 & 0.703699 & 13 & 0.054131 & 0.739168 & 29 & 0.025489 & 2.123725 & 0.044936 \\
\hline
\end{tabular}

Table 5. Results of one-dimensional test for Rsm parameter

The data are given in Graph 2.[2,8] Outlying points indicated with a red ellipse cause R2 and p to deviate from the desired values. Here, the deviations were not found to result from a gross error $( \pm 36)$, unlike those for the Ra parameter. As a consequence, they had to be included in the calculation and have led to a low validity value.

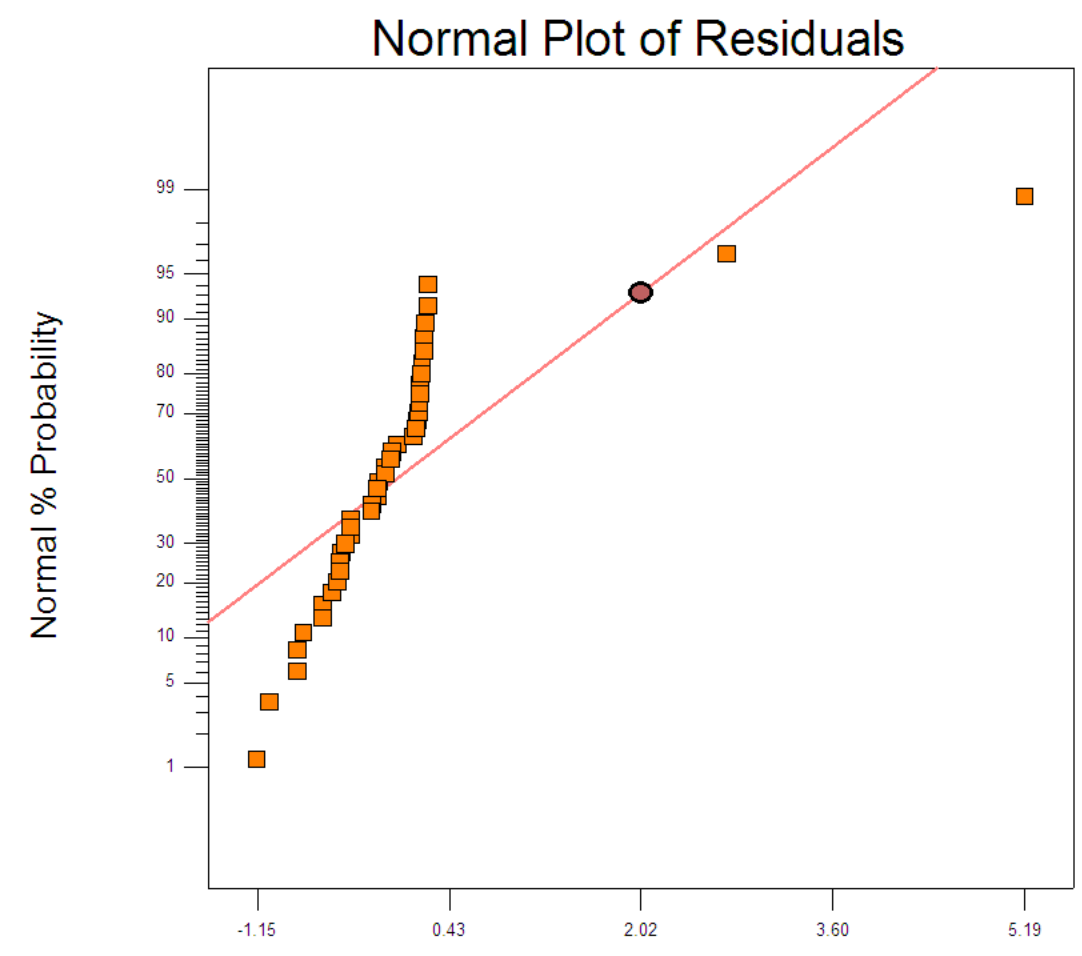

Fig. 2. Graphical verification of validity of the model for Rsm parameter

The last test involved the Rv parameter. The parameters relevant to this parameter were as follows: unknown parameter, the type of standard and, again, the effect of the software filter used. For Rv, the evaluation did not include the effect of the measuring speed, see Table 6.

\begin{tabular}{|c|c|c|c|c|c|}
\hline \multirow{2}{*}{ Effect } & \multicolumn{5}{|c|}{$\begin{array}{c}\text { One-dimensional significance test for Rv parameter [um] (ANOVA) } \\
\text { Sigma-effective hypothesis of limited parametrization }\end{array}$} \\
\cline { 2 - 6 } & SS & $\begin{array}{c}\text { Degree } \\
\text { of freedom }\end{array}$ & MS & F & p \\
\hline Unknown parameter & 627.3117 & 1 & 627.3117 & 1010.379 & 0.000000 \\
\hline A:speed [mm.s-1] & 1.0215 & 6 & 0.1703 & 0.274 & 0.944516 \\
\hline B:filter & 7.5716 & 4 & 1.8929 & 3.049 & 0.032595 \\
\hline C:standard [um] & 714.8991 & 3 & 238.2997 & 383.817 & 0.000000 \\
\hline Error & 18.0052 & 29 & 0.6209 & & \\
\hline
\end{tabular}

Table 6. Results of one-dimensional test for $\mathrm{Rv}$ parameter

In this case, the validity of the mathematical model was proved beyond doubt. Both R2 and p (Table 7) are getting close to the desired values. 


\begin{tabular}{|c|c|c|c|c|c|c|c|c|c|c|c|}
\hline \multirow{2}{*}{$\begin{array}{c}\text { Dependent } \\
\text { variable }\end{array}$} & \multicolumn{11}{|c|}{ SS test for the entire model vs. SS residuals (ANOVA) } \\
\hline & $\begin{array}{c}\text { Multiples } \\
\text { of R }\end{array}$ & $\begin{array}{c}\text { Multiples } \\
\text { of R2 }\end{array}$ & $\begin{array}{c}\text { The coefficient } \\
\text { of determination }\end{array}$ & $\begin{array}{c}\mathrm{SS} \\
\text { model }\end{array}$ & $\begin{array}{c}\mathbf{d f} \\
\text { model }\end{array}$ & $\begin{array}{c}\text { MS } \\
\text { model }\end{array}$ & $\begin{array}{c}\text { SS } \\
\text { variance }\end{array}$ & $\begin{array}{c}\mathbf{d f} \\
\text { variance }\end{array}$ & $\begin{array}{c}\text { MS } \\
\text { variance }\end{array}$ & $\mathbf{F}$ & $\mathbf{p}$ \\
\hline Rv [um] & 0.989872 & 0.979846 & 0.970812 & 875.3911 & 13 & 67.33778 & 18.00516 & 29 & 0.620868 & 108.4576 & 0.00 \\
\hline
\end{tabular}

Table 7. Results of verification test for Rv parameter

Based on the above tables, a definite conclusion can be derived that the model is valid and can be used for evaluating the effects of speed on measured values. The model can also be used for verifying the results of the previous tests.

\section{Results of the test of measuring speed}

The effects of the measuring speed were evaluated using the ANOVA analysis. With ANOVA, it is possible to establish whether values of an observable characteristic of a parameter have a statistically significant effect on values of a random quantity of that parameter. [1] In this test, the parameter is the roughness parameters Ra, Rz, Rsm and Rv, and the characteristic is the measuring speed. In the D-optimal design of the experiment, the speeds for this test were chosen at random. The range of the speeds was 0.1 to $3 \mathrm{~mm} / \mathrm{s}$, as set out in the conditions reported by the manufacturer of the Hommel Etamic T8000 machine. The speeds were chosen as follows: $0.1 ; 0.83 ; 1.07 ; 1.55 ; 2,03 ; 2.27$ and 3 mm/s. For each speed, the average measured roughness number was calculated from the measured data. Then, for each speed and average roughness combination, the variance was calculated and entered into Table 8.

\begin{tabular}{|c|c|c|c|c|c|c|c|c|}
\hline & \multicolumn{7}{|c|}{ Scheffe's test; variable: Ra [um] (ANOVA), } \\
\cline { 2 - 9 } Number & \multicolumn{7}{|c|}{ Probability for the Post Hoc Test: MS =0.01108, df $=29.000$} \\
\cline { 2 - 9 } & A:speed [mm.s-1] & $\{1\}$ & $\{2\}$ & $\{3\}$ & $\{4\}$ & $\{5\}$ & $\{6\}$ & $\{7\}$ \\
4.8300 & 2.5000 & 1.5714 & 3.2000 & 4.4000 & 4.5667 & 2.7933 \\
\hline 1 & $0.1[\mathrm{~mm} . \mathrm{s}-1]$ & & 0.006684 & 0.000000 & 0.011060 & 0.000000 & 0.000000 & 0.992926 \\
\hline 2 & $0.83[\mathrm{~mm} . \mathrm{s}-1]$ & 0.006684 & & 0.000000 & 0.000016 & 0.000000 & 0.000000 & 0.014775 \\
\hline 3 & $1.07[\mathrm{~mm} . \mathrm{s}-1]$ & 0.000000 & 0.000000 & & 0.000000 & 0.000000 & 0.000000 & 0.000000 \\
\hline 4 & $1.55[\mathrm{~mm} . \mathrm{s}-1]$ & 0.011060 & 0.000016 & 0.000000 & & 0.000000 & 0.000000 & 0.002852 \\
\hline 5 & $2.03[\mathrm{~mm} . \mathrm{s}-1]$ & 0.000000 & 0.000000 & 0.000000 & 0.000000 & & 0.707706 & 0.000000 \\
\hline 6 & $2.27[\mathrm{~mm} . \mathrm{s}-1]$ & 0.000000 & 0.000000 & 0.000000 & 0.000000 & 0.707706 & & 0.000000 \\
\hline 7 & $3[\mathrm{~mm} . \mathrm{s}-1]$ & 0.992926 & 0.014775 & 0.000000 & 0.002852 & 0.000000 & 0.000000 & \\
\hline
\end{tabular}

Table 8. Statistical evaluation for individual speeds

Table 8 shows major differences in the values of the Ra parameter from a statistical viewpoint, when comparing the speeds of 0.1 and $0.83 ; 0.1$ and $1.07 ; 0.1$ and $1.55 ; 0.1$ and $2.03 ; 0.1$ and 2,27. In the table, this is indicated by values close to zero. The only case where the difference is less striking is between the 0.1 and $3 \mathrm{~mm} / \mathrm{s}$ speeds (from a statistical perspective). On standards with lower RA roughness numbers, surface texture elements begin to be skipped at speeds as low as $2 \mathrm{~mm} / \mathrm{s}$, owing to inertial forces, leading to an alias surface. To illustrate the response of measurement cycles to changing speeds, Graph 3 is provided.

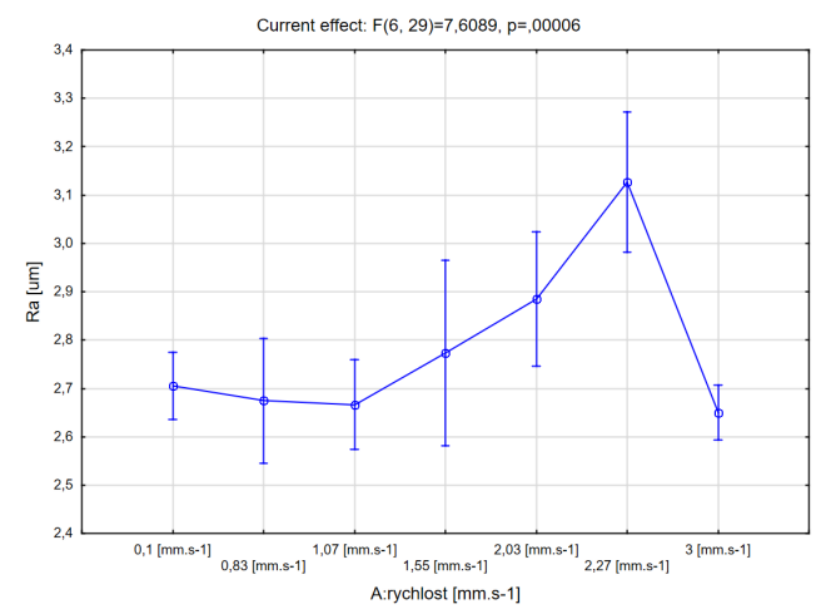

Fig. 3. Averaged Ra parameter measured at various speeds 
As Graph 4 shows, the averaged values of the Ra roughness number measured on all standards (RA) was almost constant up to the speed of $1.07 \mathrm{~mm} / \mathrm{s}$. Above $1.07 \mathrm{~mm} / \mathrm{s}$, the measured values began to increase, as did their variance. This continued up to $3 \mathrm{~mm} / \mathrm{s}$, where they returned to levels obtained at $1.07 \mathrm{~mm} / \mathrm{s}$. Although statistics show that the results are near equal for speeds from $0.1 \mathrm{~mm} / \mathrm{s}$ to $1.07 \mathrm{~mm} / \mathrm{s}$ and for $3 \mathrm{~mm} / \mathrm{s}$, it is not actually true. At speeds above $2 \mathrm{~mm} / \mathrm{s}$, the inertia of the stylus causes peaks to be skipped, leading to distorted results.

$\mathrm{Rz}$ and $\mathrm{Rv}$ parameters exhibit the same trend as Ra. This is documented in Graph 4 for Rz parameter. As the graph for $\mathrm{Rv}$ is identical, it is not included here. However, both give the same information. Up to $1.07 \mathrm{~mm} / \mathrm{s}$ the results are nearly identical. At higher speeds, the recalculated measured value increases, which is not correct in this evaluation. The rise continues up to $3 \mathrm{~mm} / \mathrm{s}$ where the values return to levels obtained at speeds below $1.07 \mathrm{~mm} / \mathrm{s}$.

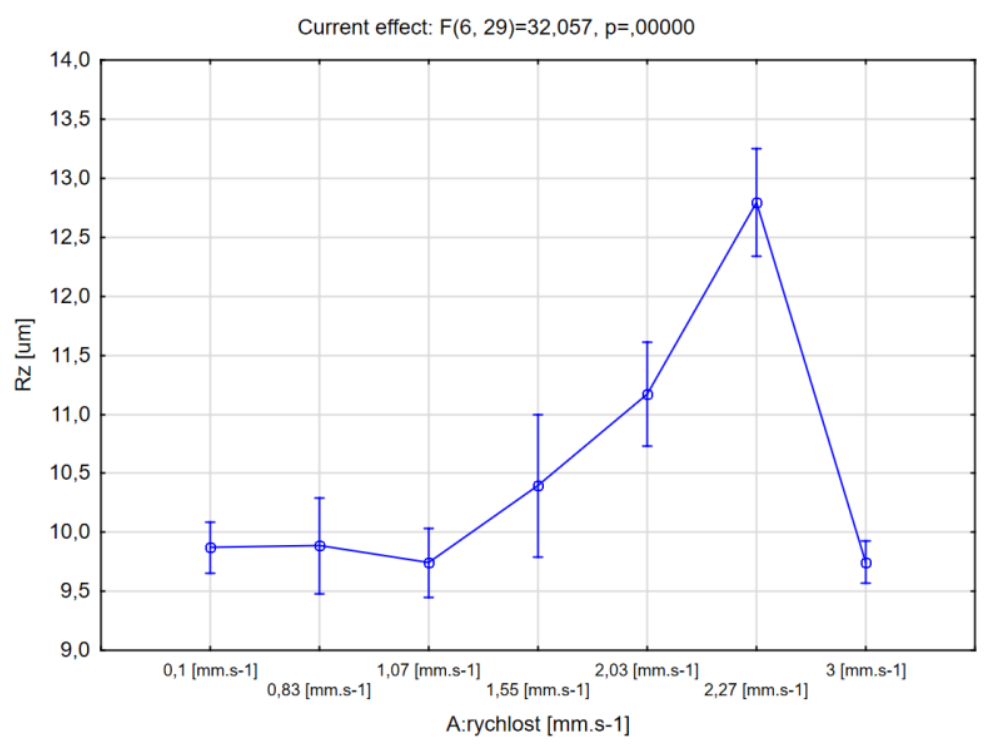

Fig. 4. Averaged Rz and Rv parameters measured at various speeds

In the Rsm parameter, the effect of speed disappears. The likely reason is the mathematical definition of this parameter, i.e. the distance between two peaks, which mean that it does not matter whether the returning stylus hits every first or very Xth peak.

\section{Conclusion}

The motivation for this article was to verify the accuracy of the machine settings when measuring surface roughness. This test is part of an extensive project to set up a software filter selection methodology for measuring surface roughness. This is solved in the framework of research at the University of West Bohemia. The test was carried out using the planned D-optimal experiment using the response surface study. A range ranging from 0.1 to $3 \mathrm{~mm} / \mathrm{s}$ was selected for the test. Here again, the effect of the scanning speed with the filter used and the change in the assessed surface roughness was tested.

The evaluation of the test was carried out in two steps. In the first step, it was evaluated whether the generated model and data measured by it were valid or not. Validation was validated using the Univariate Test of Significance and the SS Test of the Whole Model vs. residua SS "Test of SS Whole Model vs. SS Residual ", where the parameters p and $\mathrm{R} 2$ are compared to the required value. In all tests it was assessed that the model is fully valid. And on the basis of this knowledge, it was possible to continue processing the data obtained through this plan.

The actual evaluation of the effect of the sensing speed was performed using the ANOVA statistical method. Based on the findings of this test, it was reported that the Rsm scanning rate had no effect. The results for parameters Ra, $\mathrm{Rv}$ and $\mathrm{Rz}$ using a scanning speed of up to $1.07 \mathrm{~mm} / \mathrm{s}$ are almost identical. At higher speeds, all three parameters also increase the inaccuracy of the measured data and also increase the variance of the values. According to statistical processing, using the speed of $3 \mathrm{~mm} / \mathrm{s}$ (the maximum allowed speed for the machine on which the tests are performed), we obtain the same results as the speed measurements up to $1.07 \mathrm{~mm} / \mathrm{s}$. This is due to the occurrence of a surface alias and therefore non-measurement real values of surface structure.

\section{Acknowledgments}

The article has been prepared in the project LO1502 'Development of the Regional Technological Institute" under the auspices of the National Sustainability Programme I of the Ministry of Education of the Czech Republic aimed to support research, experimental development and innovation. 


\section{References}

[1] Palenčár, R.: (2001) "Uncertainty in Measurement I: Expression of Uncertainty", Automa,

[2] Guide to the Expression of Uncertainty in Measurement. BIPM, IEC, IFCC, ISO, IUPAC,IUPAP, OIML, 1993

[3] Suitability of control processes: suitability of measurement systems, suitability of measurement and control processes, expanded uncertainty, conformity assessment. Praha: Česká měnostnost pro jakost, 2011. Quality management in the automotive industry. ISBN 978-80-02-02307-4

[4] Whitehouse, D. J. Handbook of surface and nanometrology. 2nd ed. Boca Raton: CRC Press, 2011. ISBN 9781420082012.

[5] Štefan, V.:(2014) Data filtering for surface roughness measurement. Plzeň, Diploma thesis (Ing.). University of West Bohemia in Pilsen, Faculty of Mechanical Engineering. Lecturer Zdeněk Pospěch

[6] http://www.hommel-etamic.cz/cz/technicke-informace/drsnost-povrchu-dle-din-en-iso/[online]. [2016-08-27]

[7] ZEISS [online]. [cit. 2018-09-15].

[8] JIiroušek, P.: (2012) Eligibility of measurement system in the gearboxes production of Škoda auto a.s [online]. [cit. 2017-03-08].

[9] E.Clayton Teague, Fredric E. Scire, Saul M. Baker, Stephen W. Jensen, (1982)Three-dimensional stylus profilometry, In Wear, Volume 83, Issue 1, , Pages 1-12, ISSN 0043-1648, https://doi.org/10.1016/00431648(82)90335-0. Available at:http://www.sciencedirect.com/science/article/pii/0043164882903350

[10] M. Shah Mohammadi, M. Ghani, M. Komeili, B. Crawford, A.S. Milani,( 2017) The effect of manufacturing parameters on the surface roughness of glass fibre reinforced polymer moulds, In Composites Part B: Engineering, Volume 125, Pages 39-48, ISSN 1359-8368, https://doi.org/10.1016/j.compositesb.2017.05.028. Available at: http://www.sciencedirect.com/science/article/pii/S1359836816317887) 